\title{
Creación surrealista de sueños colectivos en Educación Primaria. Investigación- acción intercultural
}

\section{Surrealist creation of collective dreams in Primary Education. Intercultural action research}

\author{
Cynthia Nathaly Chocobar ${ }^{1}$ \\ cynthianathaly.chocobar@um.es \\ Universidad de Murcia, España
}

\begin{abstract}
Resumen:
INTRODUCCIÓN. Este artículo recoge una experiencia educativa de investigación-acción efectuada durante dos ciclos sucesivos de intervención didáctica con alumnado de sexto curso de Educación Primaria de dos colegios públicos situados respectivamente en Salta (Argentina) y Murcia (España). El marco teórico de esta investigación se centra en una concepción epistémica del desarrollo de la competencia en comunicación lingüística concerniente a textos literarios de índole surrealista cuya desenvoltura requiere conexión con otras competencias, lenguajes, artes y culturas. MÉTODO. La metodología cualitativa empleada, a través de cuestionarios, entrevistas y documentación didáctica de enfoque semiótico ha investigado el proceso de diseño y experimentación de una tarea compleja basada en la creación de sueños colectivos y performance onírica a partir de hipótesis fantásticas. RESULTADOS. La educación literaria de esta investigación centrada en el proyecto
\end{abstract}

\begin{abstract}
:
INTRODUCTION. This article reports an educational action-research experience carried out during two successive cycles of didactic intervention with students in the sixth year of Primary Education from two public schools located respectively in Salta (Argentina) and Murcia (Spain). The theoretical framework of this research focuses on an epistemic conception of the development of competence in linguistic communication concerning literary texts of a surrealist nature whose development requires connection with other competences, languages, arts and cultures. METHOD. The qualitative methodology adopted included questionnaires, interviews and didactic documentation with a semiotic approach to investigate the process of design and experimentation of a complex task based on the creation of collective dreams and oneiric performance based on fantastic hypotheses. RESULTS. The idea of literary education implemented in this piece of research complied with
\end{abstract}

1 Dirección para correspondencia (correspondence address):

Cynthia Nathaly Chocobar. Universidad de Murcia. Departamento de Didáctica de la Lengua y la Literatura. Facultad de Educación. Campus de Espinardo, s/n. 30100 Murcia (España). 
Creación surrealista de sueños colectivos en Educación Primaria. Investigación-acción intercultural

Cynthia Nathaly Chocobar

imaginario surrealista se ha materializado en las aulas hallando evidencias del cumplimiento de la hipótesis de trabajo. DISCUSIÓN. La educación literaria de esta investigación centrada en el proyecto imaginario surrealista se ha materializado en las aulas a través de experiencias didácticas de interacción significativa entre el mundo lector y el de la obra literaria, postulando un modelo educativo que potencia la creatividad, la autoestima y el empoderamiento de los aprendices en edad escolar.

\section{Palabras clave:}

Creación surrealista; Educación Primaria; investigación-acción; interculturalidad. the working hypothesis. DISCUSSION. The idea of literary education implemented in this research based on the surrealist imaginary project crystalized in the classrooms through didactic experiences of significant interaction between the reading world and that of the literary work, postulating an educational model that enhances creativity, self-esteem and the empowerment of school-age learners.

\section{Key words:}

Surrealist creation; Primary Education; action research; interculturality.

\section{Résumé:}

1. INTRODUCTION. Cet article présente une expérience pédagogique-action-recherche menée au cours de deux cycles successifs d'intervention didactique auprès d'élèves de sixième année de l'enseignement primaire de deux écoles publiques situées respectivement à Salta (Argentine) et à Murcie (Espagne). Le cadre théorique de cette recherche se concentre sur une conception épistémique du développement de la compétence en communication linguistique concernant des textes littéraires à caractère surréaliste dont la désinvolture nécessite une connexion avec d'autres compétences, langues, arts et cultures. MÉTHODE. La méthodologie qualitative utilisée, à travers des questionnaires, des entretiens et une documentation didactique avec une approche sémiotique, a étudié le processus de conception et d'expérimentation d'une tâche complexe basée sur la création de rêves collectifs et de performances oniriques à partir d'hypothèses fantastiques. RÉSULTATS. L'éducation littéraire de cette recherche centrée sur le projet imaginaire surréaliste s'est matérialisée dans les salles de classe, au travers de preuves conformes avec I'hypothèse de travail. DISCUSSION. L'éducation littéraire de cette recherche centrée sur le projet imaginaire surréaliste s'est matérialisée dans les salles de classe à travers des expériences didactiques d'interaction significative entre le monde de la lecture et celui de l'œuvre littéraire, postulant un modèle éducatif qui valorise la créativité, l'estime de soi et l'autonomisation des apprenants d'âge scolaire.

\section{Mots clés:}

Création surréaliste; enseignement primaire; recherche-action; interculturalité.

Fecha de recepción: 05-11-2018

Fecha de aceptación: 06-11-2018 


\section{Marco teórico}

Este trabajo de investigación se enmarca en una concepción epistemológica de la educación que se basa en la interacción de competencias para el fomento del conocimiento en acción a partir de tareas contextualizadas en situaciones donde se promueve un aprendizaje significativo y estratégico que moviliza los saberes con voluntad de transformación creativa y de transferencia social (Pérez, 2007; Jonnaert, Barrette, Boufrahi y Masciotra, 2005; González, 2013, pp. 39-40).

Su prioridad es poner como centro de interés del proceso de enseñanza/aprendizaje a los alumnos en tanto que personas con vidas singulares y en convivencia sostenible a partir de iniciativas heurísticas e innovadoras provenientes de decisiones colaborativas de índole democrática (Achaerandio, 2010; Murga-Menoyo, 2015, pp. 61-62). Para lograrlo, tal y como queda estipulado a escala global desde la orientación del proyecto Tuning Educational Structures in Europe (González y Wagenaar, 2006, pp. 17), es necesario activar las competencias en su dimensión sistémica, es decir, cultivando la integración de las partes en el todo dinámico. Desde tal sentido institucional, las competencias se nutren de un mismo marco conceptual avalado por la OCDE (2005) y afianzado por estudios nacionales e internacionales sobre el tema, de los que se desprende un trazado diáfano de lo que debieran ser buenas prácticas de su proceso didáctico y evaluador (Roegiers, 2007; Moya y Luengo, 2011; Perrenoud, 2012; Casanova, 2012).

Al respecto, en la dinámica transversal de las competencias tiene preeminencia la competencia en comunicación lingüística que reúne capacidad y práctica contextualizada en su desenvoltura discursiva (Bachman, 1995). Estos discursos son competentes si se efectúan en contextos multimodales de los que emergen actos auténticos de comprensión y de expresión creativa y crítica de textos novedosos atendiendo a los profundos cambios culturales que se están produciendo en los entornos mediáticos donde, desde las últimas décadas, emerge la Sociedad del Conocimiento (UNESCO, 2005; Caro, 2018; Colás, de Pablos y Ballesta, 2018).

Es por ello que PISA (Programme for International Student Assessment) propone desde los inicios del siglo XXI hasta su edición más reciente una intensificación creciente del uso estratégico de las TIC en el tratamiento de la comprensión lectora en las aulas (Schleicher, 2006; OCDE, 
Creación surrealista de sueños colectivos en Educación Primaria. Investigación-acción intercultural

Cynthia Nathaly Chocobar

2009; Lorenzo, 2016), lo cual no significa confundir el medio con el lenguaje sino liberar el sentido y la coherencia del lector de las ataduras del significado único y del texto autoritario, pues tal es la dinámica del hipertexto (Landow, 1996; Mendoza, 2012), donde escritores y lectores se mueven entre redes escogidas por ellos mismos en un proceso electivo que convierte lectura y escritura en actos netamente creativos y con posibilidades didácticas de intervención social, ya que desde las nuevas oportunidades que brinda la Web 2.0 lo importante en la educación digital es discernir que no se trata de usar artilugios tecnológicos de última generación sino de emplearlos intelectualmente de modo estratégico y personalizado en función del desarrollo de las altas capacidades cognitivas y comunicativas del usuario para dar cuenta del mundo en su complejidad (Morin, 1999; Prensky, 2015; Valverde, 2015).

Ello es coherente con las expectativas del informe Teaching and Learning. Towards the Learning Society de la European Commission (1996) donde quedó definido el aprendizaje para la vida en su recurrencia tanto a los entornos formales de la escuela como a los informales de la convivencia familiar, a fin de que los aprendizajes sirvieran para saber gestionar las situaciones problemáticas e imprevisibles que son habituales en la vida cotidiana. Todos los informes que la OCDE emitió en décadas posteriores procuran mantener este principio socioeducativo de carácter humanista. Así pues, plantear las acciones didácticas con aspiración a realizar experiencias vivas de aprendizaje invita a trabajar desde una metodología basada en proyectos (Trujillo, 2016) tareas en las que el alumnado emprenda la realización creativa de ideas propias y colectivas haciendo uso de su comprensión y expresión lingüísticas asociadas semióticamente a otros lenguajes y en circunstancias favorables a la interacción dialógica entre participantes con fines constructivos y democráticos.

El cultivo de la creación en la educación ha de perseguir tales fines (Guilford, J. P., 1991; Torrance, 1988; De la Torre y Violante, 2006; Klimenko, 2008). Desde la inventiva propia y la voluntad de conjugar este conocimiento con los compañeros para hacer una obra colectiva, el alumnado aprende creativamente a emprender proyectos aprovechando la diversidad de aportaciones y perspectivas. El estudiante no se siente así como individuo competidor sino como miembro de una comunidad de aprendizaje (Marín y Soler, 2004) que tiene responsabilidades transformadoras en relación con su aprendizaje cooperativo, el cual, con el 
propósito de interaccionar para alcanzar metas de calidad, como resume Llopis (2011, p. 41), implica varias acciones: "Se coordinan esfuerzos, se aportan ideas y conocimientos, se comparten habilidades y se llegan a tomar decisiones por consenso". De este modo es viable emprender cooperaciones de carácter inclusivo tanto en el ámbito interdisciplinar (Lavega, Sáez de Orcáriz, Lasierra y Salas, 2013) como en el intercultural (Díaz-Aguado, 2003), las cuales amplían en gran medida las posibilidades innovadoras del aprendizaje basado en competencias en beneficio de la formación integral.

En el espacio científico de la educación literaria, gracias a la recursividad natural de la lengua imaginativa para acoger cualquier tipo de tema, son eficaces las iniciativas de trabajo cooperativo con voluntad interdisciplinar, tal y como lo demuestran las diversas experiencias de creación literaria coordinadas por la profesora Caro en las etapas de Educación Primaria y Educación Secundaria a partir del centro de interés de los clásicos hispánicos (Caro, 2014). La competencia literaria, considerada en su doble dimensión de producción e interpretación de textos literarios, es idónea para el cultivo cognitivo y artístico de la lengua con proyección significativa hacia la vida del aprendiz y demanda que los enseñantes actúen como mediadores de su proceso adecuado (Amo, 2009).

Concepto clave para impulsar este proceso es el "intertexto lector", pues asocia los contenidos del texto con el bagaje cultural del lector, ya que por él "se integran y se combinan las aportaciones personales y las resultantes de un aprendizaje específico" (Mendoza, 2001, p. 104). Como el intertexto lector impulsa la capacidad interpretativa desde su inicio, justo cuando el conocimiento humano comienza a establecer conexiones semánticas por las que puede comprender lo no dicho y lograr síntesis integradas del contenido, su educación en el ámbito literario propicia el que la literatura pueda establecer contactos con otras artes, como la música (De Vicente-Yagüe, 2013; 2014), el cine (Romea, 2001; 2011; González, 2015a; 2015b; Amo, 2004) o la pintura (Molina, 2015; Guerrero, 2008; Guerrero, 2015), y por tales interconexiones estimula las capacidades intermedias que son indispensables para lograr las altas capacidades cognitiva y crítica.

También la interculturalidad se abre paso didáctico en las propuestas literarias de orientación semiótica intertextual (Ballester, Ibarra, Mínguez y Morote, 2007), y en especial las prácticas de creación li- 
Creación surrealista de sueños colectivos en Educación Primaria. Investigación-acción intercultural

Cynthia Nathaly Chocobar

teraria y de dramatización en el aula cobran relevancia intercultural y ética en la construcción de la ciudadanía (Tejerina, 2008). El saber ser en el saber y el saber hacer con una expresión clave: diálogo solidario. El Libro Blanco sobre el Diálogo Intercultural editado por el Consejo de Europa (2008) esclarece nociones en este sentido, dando especial relevancia a las estrategias comunicativas de intercambio abierto y respetuoso de opiniones, capacidad de expresión libre y de escucha atenta del discurso ajeno, ya que sus objetivos son comprensivos y coparticipativos con la alteridad en el marco convencional de los Derechos Humanos.

En relación con la educación literaria intercultural, González apunta la voluntad de superar la dialéctica de los opuestos para lograr una auténtica comunicación integradora de multiplicidades y cambios y, por ello, recomienda: "El empleo comunicativo de los textos literarios a través de foros y de talleres lectoescritores de carácter significativo abre paso a la inclusión expansiva e interactiva de todos los mundos posibles dentro y fuera del aula y al provecho de su riqueza en culturas y convivencia" (González, 2015b, p. 417). Así pues, importa planificar la investigaciónacción en el aula con acciones comunicativas que procuren la conexión entre culturas dentro del aula y la educación en valores democráticos, lo cual depende de la voluntad didáctica y humana del profesor pero también de la voluntad institucional del equipo directivo del Centro educativo donde trabaja. Sin duda, tal empeño debería ser parte de la identidad de todo el Centro educativo, ya que, como alega Touriñán López (2008, p. 36), la educación en valores y en actitudes para la interculturalidad es un "elemento fundamental para el éxito de la integración en el mundo, para promover y proteger la identidad cultural y para conseguir personas autónomas capaces de defender y promover los derechos en un mundo globalizado". Con esta expectativa, se procura la mejor dinámica verbal para el desenvolvimiento pacífico y enriquecedor de tales situaciones de conjunción. Es así como González di Pierro propone, desde bases etnográficas, la educación intercultural con actos de competencia participativa en Educación Primaria (González di Pierro, 2014).

El lenguaje artístico del surrealismo aplicado a la educación literaria tiene gran eficacia en la asunción de obras creativas en las etapas obligatorias, tal y como ha demostrado en otras investigaciones la autora de este artículo (Chocobar, 2014; Chocobar, 2014b; Chocobar, 2015a; Chocobar, 2015b; Chocobar, 2015c), ya que esta es una línea de investi- 
gación emergente en la que apenas existen antecedentes sobre tal iniciativa y los de Chocobar son punteros en el panorama internacional. El surrealismo no pretende imitar la realidad sino provocar la risa rompiendo con la convención (Chavot, 2001). En efecto, la retórica del nonsense produce humor surrealista que guarda concomitancias con la afición infantil por el juego de la fantasía con acciones retóricas del mundo al revés al estilo de las que Lewis Caroll expresó en Alicia en el país de las maravillas (Romea, 2010). La asociación de lo dispar proveniente de las teorías freudianas sobre el witz (chiste por junción de lo dispar) en el inconsciente para ver el mundo convencional al revés produce asombro ante el ingenio disparatado (Caro, 1999), pues en él se aloja el origen de la poesía. Antecedente ejemplar en los talleres de creación literaria es Gianni Rodari, cuya Gramática de la fantasía es célebre por los binomios fantásticos y las hipótesis fantásticas que lúdicamente desatan visiones inusitadas de los clásicos de la literatura infantil recreados en la mente surrealista de los niños (Rodari, 2011).

\section{Marco empírico}

\section{Metodología}

Este trabajo se ha desarrollo según los protocolos científicos de la metodología cualitativa interpretativa de investigación-acción (Kemmis, 1989; Latorre, 2013), la cual es idónea para estudiar en el proceso sucesivo de dos ciclos de intervención didáctica con su correspondiente planificación y análisis reflexivos dos propuestas educativas similares desarrolladas con voluntad intercultural en colegios de países vinculados por el idioma español. Tal metodología cualitativa también es adecuada para rescatar y analizar información sobre las estrategias intertextuales y de aprendizaje colaborativo en el aula que responden a una proyección humanista y democratizadora de la educación literaria (Albert Gómez, 2006, p. 222). Esta metodología educativa difiere de las prácticas academicistas ancladas en modelos conductistas y funcionales que impiden el desarrollo de procedimientos heurísticos y holísticos y propone un modelo innovador al respecto que los impulsa de modo competente. 


\section{Participantes}

Los participantes de esta investigación han sido alumnado de tercer ciclo de Educación Primaria ( $6^{\circ}$ curso) ubicados en dos provincias de España (CEIP Ricardo Campillo de Santomera, Murcia, líneas A y B) y Argentina (Colegio Público Nuestra Señora del Milagro de Limache, Salta, líneas A y B). El alumnado español del grupo A presenta gran diversidad cultural y cognitiva: 2 de procedencia extranjera, 5 de educación compensatoria, 1 disléxico, 1 con TDH y 2 con altas capacidades. En el Grupo B hay 2 disléxicos, 1 con TDH, 1 con sordera y 4 de familias de origen extranjero. No se han detectado casos de desconocimiento del idioma. El absentismo es inexistente, razón que nos permitió actuar con todos los participantes. En ambos grupos intervinieron las maestras en calidad de observadoras en el aula, y también los padres y las madres de los discentes en calidad de observadores en el ámbito familiar. Con respecto a las características del alumnado argentino, en el grupo A no se observa ningún caso que denote necesidades educativas especiales, tan solo un aprendiz con problemas de integración en el grupo. En el grupo B se halla 1 niño que presenta retraso madurativo leve y otro que tiene conductas disruptivas y agresivas. En ambos grupos existen casos notorios de absentismo escolar, aunque, debido a su motivación en la realización de las tareas, el absentismo desapareció y todos los aprendices participaron en el proyecto.

\section{Hipótesis}

Con el fin de proponer soluciones específicas para la mejora contextualizada de la competencia en comunicación lingüística del alumnado participante, se ha postulado la hipótesis de esta investigación en los siguientes términos: si investigamos didácticamente las posibilidades formativas de la retórica del surrealismo en la creación de sueños colectivos con alumnado de Educación Primaria, lograremos un modelo educativo que por la interacción de textos y culturas fomente la creatividad literaria de los discentes tanto en sus prácticas comprensivas y expresivas como en la autoestima y el empoderamiento que estas comportan. 


\section{Objetivos}

He aquí el objetivo general de la investigación que responde a las expectativas de consecución de la hipótesis formulada, así como los objetivos específicos que articulan su logro adecuado:

- Objetivo general:

Desarrollar la competencia en comunicación lingüística y literaria del alumnado participante en la investigación a través de un modelo didáctico de creación literaria surrealista cooperativa e intercultural.

- Objetivos específicos:

1. Activar la creatividad literaria del alumnado participante asumiendo transformaciones que aprovechen la diversidad de sus aportaciones y perspectivas.

2. Promover la educación literaria surrealista por medio de tareas didácticas y lúdicas de proyección dialógica donde opere la metodología intertextual de los sueños y de la hipótesis fantástica de base sinéctica.

3. Incentivar la invención personal y colectiva empleando la comprensión y la expresión lingüísticas asociadas semióticamente a otros lenguajes en circunstancias favorables a la interacción dialógica entre participantes.

4. Profundizar en la transmodalización genérica por vía de la dramatización de los textos surrealistas elaborados por los alumnos con la consecución de una performance difundida en la comunidad educativa.

\section{Instrumentos}

Según su funcionalidad, se han elegido los siguientes instrumentos:

- Instrumentos de recolección de datos y de evaluación: cuestionarios inicial y final sobre las preferencias literarias y desarrollo de la creatividad del alumnado participante; entrevista a las docentes tutoras y personal directivo del Centro. Los cuestionarios han sido diseñados en atención a los objetivos de la investigación para proporcionar información significativa de los discentes sobre gustos literarios y capacidades literarias creativas, grado de interés y de contacto familiar con obras surrealistas y acciones inventivas al 
respecto. Su contenido y los ítems designados como indicadores de medición fueron validados por doctoras expertas en el tema de exploración, lo cual permitió adecuar la coherencia temática (Alaminos Chica y Castejón Costa, 2006) con los objetivos planteados para realzar la importancia de la creatividad en educación (Iglesias-Cortizas y Rodicio García, 2013).

- Instrumentos didácticos: la creación de los relatos oníricos ha contado con fragmentos de los vídeos Los lugares del sueño editado por el Museo Nacional Centro de Arte Reina Sofía y Cómo hacer arte surrealista del canal Artetrack. También se ha empleado el visionado en pizarra digital interactiva de imágenes de cuadros surrealistas de Salvador Dalí, René Magritte y Remedios Varo. En la performance onírica se han utilizado fragmentos de los vídeos Los lugares del sueño (Museo Nacional Centro de Arte Reina Sofía) y Performance Air Primaria (UAM), así como carteles y dibujos sobre el personaje elegido por los discentes para representar la obra de creación colectiva, la pizarra digital interactiva; los objetos surrealistas creados por los discentes en otra propuesta investigadora realizada por la autora de este artículo; escenografía móvil y disfraces para la caracterización.

- Instrumentos de registro de la tarea compleja: dada la corta edad del alumnado participante en la intervención, ha sido necesario registrar minuciosamente sus intervenciones creativas del alumnado participante a través de la observación participante docente sobre las actuaciones discentes en el aula, así como de grabaciones en vídeo y audio.

\section{Proceso de investigación-acción intercultural}

El proceso de investigación-acción ha partido del diseño de las estrategias de actuación (planificación/organización de las intervenciones) recogidas en un cronograma que ha marcado la temporalización y la secuenciación de las tareas. Se ha dividido en dos fases de investigación: la primera ha sido aplicada con alumnado argentino y la segunda con alumnado español.

- Primera fase de intervención: la tarea compleja propuesta al alumnado argentino iba dirigida hacia la presentación ante la comunidad educativa de una performance onírica creada por los discentes. Para tal 
propósito se han formulado en cada grupo (A y B) una serie de subtareas articuladas entre sí a fin de facilitar la consecución última de la tarea compleja propuesta. Fueron cinco las sesiones realizadas al respecto: la primera se dedicó a la presentación de la propuesta y el pase de vídeos sobre el surrealismo y de imágenes de pinturas de artistas destacados al respecto, tras lo cual hubo un coloquio de todo el grupo sobre su mensaje y valores artísticos. En la segunda sesión se invitó al alumnado a rememorar un sueño o una pesadilla para dibujarlo en un folio de manera individual. La tercera se dedicó a la escritura creativa surrealista: idearon y redactaron en grupos de cinco participantes el sueño colectivo a partir de los sueños individuales previos. La cuarta sirvió para la presentación del sueño colectivo a la clase en el contexto de foro literario y con lectura de las obras literarias frente a un atril. Por último, la quinta sesión fue empleada en la presentación de las obras discentes creadas en el taller ante la comunidad educativa en el marco escolar de la denominada "Exposición surrealista".

- Segunda fase de intervención: la tarea compleja propuesta al alumnado español ha pretendido, además de la creación de un sueño colectivo surrealista como el elaborado con el alumnado argentino, la actividad añadida de una dramatización que fue suscitada debido al interés y la gran motivación demostrada por estos participantes, que demandaban más actividades al respecto. Así pues, se ha ampliado la propuesta con una performance onírica de los relatos creados. Para ello se han formulado en cada grupo ( $\mathrm{A}$ y $\mathrm{B})$, al igual que en la fase anterior, una serie de subtareas articuladas entre sí con el objetivo de facilitar la consecución de la tarea compleja propuesta. Las cuatro primeras sesiones han efectuado el mismo protocolo que en la fase anterior. En la quinta sesión se ha efectuado un sondeo de conocimientos previos sobre dramatización, el visionado de los instrumentos didácticos (vídeos El lugar de los sueños: Performance Air-Primaria; Nubes) y un foro para comentar el mensaje didáctico a partir del material audiovisual recibido. La sexta sesión se ha dedicado a la adaptación de las obras creadas en las anteriores sesiones para realizar las performances, el reparto de personajes y de otros cometidos escénicos, así como del diseño de la escenografía. En la séptima se han confeccionado escenografía y disfraces para la actuación, En la octava se ha ensayado grupalmente la performance. $Y$ finalmente se ha dedicado la novena sesión a la presentación de la performance ante los grupos-clase (A y B). 


\section{Análisis interpretativo de los resultados}

A través del cuestionario inicial se ha recabado información sobre las preferencias literarias, los hábitos lectores, la afición por inventar historias, los tipos de historias para inventar, el autoconcepto sobre creatividad en lo dispar, las creencias sobre la noción del surrealismo, la preferencia creativa plástica, los motivos de la preferencia creativa, la preferencia comunicativa oral sobre creatividad, los motivos de la preferencia comunicativa oral sobre creatividad, los conocimientos previos sobre performance y las preferencias sobre sistema de trabajo en el aula (solo, en pequeño grupo, en gran grupo). A través del cuestionario final se ha ahondado en las mismas cuestiones y sus variaciones después de haber realizado la intervención didáctica propuesta. El análisis contrastivo de las respuestas discentes otorgadas respectivamente ha permitido valorar su grado de implicación en las tareas realizadas y la validez de la hipótesis en la praxis educativa.

Se presenta aquí una síntesis del análisis interpretativo de los resultados de la investigación en atención a su incidencia en los objetivos específicos de la misma:

- El análisis contrastivo de los resultados obtenidos en relación al propósito del objetivo específico 1 revelan que ha sido posible crear conexiones entre culturas con actos que favorezcan la creatividad literaria de los participantes y asumiendo acciones transformadoras en provecho de la diversidad de aportaciones y perspectivas del alumnado participante. En efecto, cabe interpretar que en ambos ciclos de investigación acción se ha constatado la idoneidad de la estrategia desarrollada en ambos grupos participantes, tanto los españoles como los argentinos, pues el intercambio abierto de opiniones entre estos países ha propiciado un vínculo intercultural entre pares que les ha impulsado a desarrollar hábitos de convivencia reivindicadora de la diferencia como valor, como sinergia que integra y reúne. Por tanto, la tarea compleja efectuada en ambos ciclos ha servido para reunir las perspectivas y aportaciones diversas en una unidad sistémica de educación literaria que responde plenamente a las expectativas de la OCDE sobre el perfil idóneo de la educación en competencias clave.

- En cuanto a la consecución del objetivo específico 2 se advierten también resultados positivos en la promoción de la educación literaria surrealista por medio de las tareas didácticas de proyección dialógica 
con estrategias lúdicas del agrado discente. El análisis interpretativo del decurso procesual de la investigación-acción en ambos ciclos y de las obras creativas de los discentes resultantes en ambos países permite deducir la praxis de excelencia que reporta el empleo de la metodología intertextual basada en la retórica surrealista y de la hipótesis fantástica de base sinéctica (Gordon, 1963) para fomentar el pensamiento conectivo discente entre obras y entre personas para lograr obras auténticamente colectivas. Sin duda, en tales resultados han influido favorablemente dos factores: trabajar en un proyecto común que trasciende el individualismo academicista con un proyecto común no solo de aula sino también interinstitucional y emplear estratégicamente la conexión de lo dispar para trabajar la ideación, la deliberación y el consenso grupal en la creación literaria.

- El tercer objetivo específico de la investigación-acción se ha desarroIlado convenientemente gracias a la promoción efectiva de experiencias vivas de aprendizaje significativo donde los participantes han inventado de modo colaborativo y personalizado narraciones colectivas que siguen la retórica de los sueños desde presupuestos freudianos en trasposición didáctica (el witz o junción de contrarios). Aunque no han seguido la lógica del discernimiento dialéctico, sino la de la asociación sinéctica, no por ello han dejado de ejercer con éxito su capacidad comprensiva e interpretativa en su lectura de textos audiovisuales y literarios demostrada en sus comentarios durante los coloquios así como en el provecho artístico que han dado a sus lecturas en las creaciones literarias realizadas. Se deduce, por tanto, que ha sido un acierto metodológico de este modelo adoptar un enfoque semiótico en la concepción de la educación literaria, pues ello ha permitido reportes instrumentales venidos de otros lenguajes y artes como organizadores previos para la inspiración discente que, gracias a su valor formativo y mediación significativa, han operado a favor de una interacción dialógica fluida entre los participantes.

- Finalmente, la decisión de añadir una tarea al plan de intervención del segundo ciclo de investigación-acción con alumnado español y de dar así viabilidad al desarrollo del objetivo cuarto de este trabajo permite interpretar a partir de los fenómenos observados en el aprendizaje de dicho alumnado que la culminación de la tarea compleja ha sido más rica en competencias dinamizadas en el caso español que en el argentino, pues la transmodalización genérica de los textos narrativos surrealistas de elaboración discente en textos dramáticos de pretensión 
artística semejante y basados en la soltura inventiva e imprevisible de la performance ha reforzado el carácter hipertextual de dicha tarea con la implicación de varios lenguajes verbales y no verbales en el acto dramático y ha intensificado el carácter vanguardista de su estética al combinar elementos interartísticos diversos en un espectáculo en vivo donde el flujo imaginativo ha generado poesía visual. El hecho de haber difundido la obra narrativa y su performance en la comunidad educativa ha contribuido doblemente al empoderamiento discente por la generación de obras literarias producidas por los aprendices que da fuerza expresiva a su voz personal y por el reconocimiento de la misma que también comporta la comunicación social del conocimiento educativo y artístico generado.

\section{Conclusiones}

Tras el análisis interpretativo de los resultados, se comprueba la factibilidad de la hipótesis de la investigación para mejorar la competencia lingüística del alumnado participante desde el ejercicio estratégico intensificado de la competencia literaria entendida como lengua con valor artístico por vía de la imaginación. Ello se efectúa desde una propuesta innovadora en el panorama de la educación literaria internacional por haber puesto en práctica un modelo de creación literaria surrealista que no se ha limitado al simple ejercicio de actividades sueltas con incursión en extrañezas aisladas y sin perspectiva de continuidad, antes bien se ha realizado en un proceso de investigación-acción de alcance intercultural desarrollado en dos ciclos de investigación acción, el primero en Argentina y el segundo en España, y en ambos casos con alumnado del mismo nivel educativo. Cada uno de estos ciclos ha seguido un proceso de enseñanza-aprendizaje iniciado con la conexión significativa del alumnado con la tarea, el cual ha avanzado con el coloquio de experiencias creativas compartidas y ha culminado de modo lúdico y reflexivo con la generación de las obras propias de los aprendices y la transferencia de conocimiento de las mismas a través de su comunicación a la comunidad educativa correspondiente.

Así pues, la creación surrealista de sueños colectivos en Educación Primaria ha sido un proteico taller de indagación didáctica en las posibilidades formativas del surrealismo desde la metodología interactiva 
poliédrica que en las dos dimensiones de la competencia comunicativa -oral y escrita- enmadejadas en la tarea compleja desarrollada han proporcionado el diálogo, la intertextualidad, la conexión interartística y el encuentro intercultural. Las buenas prácticas logradas en tal investigación-acción, atendiendo no solo a la competencia comunicativa sino también a la motivación y el empoderamiento discente suscitados a partir de ello, permiten afianzar la propuesta modélica de la tarea compleja reseñada para emprender proyectos educativos de este tipo. El análisis interpretativo de los resultados de la investigación a la luz de los objetivos específicos ha puesto en evidencia su consecución adecuada a las expectativas, y, por tanto, ha dado razón de ser a la concesión del objetivo general que da apoyo básico a la hipótesis y cuyas incidencias acaban de ser comentadas.

Los alumnos y alumnas participantes y las profesoras observadoras han reconocido haber descubierto su capacidad creativa usando la retórica del surrealismo en la modalidad de la hipótesis fantástica para apreciar que tienen ideas originales en su invención de historias y que en el surrealismo no se juzgan las obras literarias por su grado de corrección sino por su grado de innovación en tanto que redescubrimiento desautomatizado del mundo más allá de la realidad acostumbrada. El surrealismo no inhibe a los estudiantes, sino que los estimula en el juego colectivo de propuestas significativas para transformar el mundo. Por esta virtud es coherente con la metodología del dialogismo diseñada por Bajtín (1979), según la cual las obras literarias poseen un entramado polilógico que ha sido tejido por la colectividad cooperante. Empezar siempre la tarea por la asamblea da paso a la intervención del azar y de la motivación significativa, condiciones ambas indispensables para que la creación literaria no se aparte del aprendizaje para la vida. Y acabarlas del mismo modo afianza la autoestima y el empoderamiento discente. Entre el inicio y el final, el intermedio de las tareas literario-plásticas ha despertado lo sueños despiertos de los aprendices y les ha lanzado con fluidez ágil hacia la expresión competente de sus propios inventos habiendo comprendido previamente los textos leídos desde el método del topdown, que explora el significado desde el intertexto y las emociones del lector (Caro, 2015). El hecho de haber podido postular sueños colectivos a partir de los individuales demuestra que el surrealismo no es simple pirueta vanguardista sino una fuerza libre de la imaginación capaz de fundar sinergias poderosas, desde una coherencia que trasciende 
Creación surrealista de sueños colectivos en Educación Primaria. Investigación-acción intercultural

Cynthia Nathaly Chocobar

la lógica de la costumbre, para aborda la incertidumbre dando sentido al sinsentido.

En suma, la educación literaria de esta investigación centrada en el proyecto imaginario surrealista se ha materializado en las aulas a través de experiencias didácticas de interacción significativa entre el mundo lector y el de la obra literaria en un proceso dialogante entre personas, culturas, textos y tareas que se ha nutrido de las acciones holísticas de interpretación y de voluntad creativa presididas por el cultivo de la imaginación en actos comprensivos y expresivos de intención literaria donde cobran relevancia las palabras escritas por Octavio Paz en su ensayo La búsqueda del comienzo (escritos sobre el surrealismo) (Paz, 1974, p. 37): "La poesía siempre ha sido hecha por todos".

\section{Referencias}

Achaerandio, L. (2010). Competencias fundamentales para la vida. Guatemala: Universidad Rafael Landívar.

Alaminos Chica, A. y Castejón Costa, J. L. (2006). Elaboración, análisis e interpretación de encuestas, cuestionarios y escalas de opinión. Alicante: Universidad de Alicante

Albert Gómez, Ma. J. (2006). La investigación educativa. Claves teóricas. Madrid: McGraw Hill.

Amo, J. M. de (2004). Los textos audiovisuales en la educación literaria. Textos de didáctica de la lengua y la literatura, 35, 102-118.

Amo, J. M. (2009). El lector modelo en la narrativa infantil: claves para el desarrollo de La competencia literaria. Textos de didáctica de la lengua y la literatura, 51, 29-43.

Bachman, L. (1995). Habilidad lingüística comunicativa. En M. Llobera (Coord.). La competencia comunicativa, (pp. 105-129). Edelsa: Madrid.

Bajtín, M. (1979). Estética de la creación verbal. México: Siglo XXI.

Ballester, J., Ibarra, N., Mínguez, X. y Morote, P. (2007). Aproximación a un glosario sobre educación literaria intercultural. Lenguaje y Textos, 26, 205-225.

Casanova, Ma A. (2012). La evaluación de competencias básicas. Madrid: La Muralla.

Caro, M. T. (1999). La escritura del otro. Murcia: Universidad de Murcia.

Caro, M. T. (2014). La educación literaria de los clásicos y su proyección interdisciplinar para el aprendizaje basado en competencias. Educatio Siglo XXI, 32 (3), 31-50. http:// dx.doi.org/10.6018/j/202141

Caro, M. T. (2015). Lengua escrita. Los procesos de comprensión y expresión escritas. En Guerrero, P. y Caro Valverde, Ma T. et al (Coords). (2015). Didáctica de la Lengua y la Educación Literaria (141-157). Murcia: Pirámide.

Caro, M. T. (2018). La comunicación argumentativa en la Sociedad del Conocimiento, clave del liderazgo distribuido para un cambio educativo desde el desarrollo pro- 
Creación surrealista de sueños colectivos en Educación Primaria. Investigación-acción intercultural

Cynthia Nathaly Chocobar

fesional. RED. Revista de Educación a Distancia,. 56. Recuperado de https://www. um.es/ead/red/56/caro.pdf

Chavot, P. (2001). L'ABCdaire du Surrealisme. Paris: Flammarion.

Chocobar, C. M. (2014a). Educación literaria de humor surrealista para la infancia. Antecedentes y estado actual de la cuestión. En A. B. Mirete y M. Sánchez (Eds.). Investigación en Educación Infantil para la mejora educativa (pp. 179-191). Murcia: Editum.

Chocobar, C. M. (2014b). Comunicar para conectar, reír y jugar. Metodología intertextual de la creación literaria basada en la lógica de los sueños. En P. Miralles y T. Izquierdo (Eds). Propuestas de innovación en Educación Infantil (pp. 141-153). Murcia: Editum.

Chocobar, C. M. (2015a). Trasponiendo mundos: Microrrelatos fantásticos de pinturas surrealistas en Educación Infantil. En P. Miralles; M. Alfageme y R. Rodríguez (Eds). Investigación e Innovación en Educación Infantil (pp. 261-272). Murcia: Editum.

Chocobar, C. M. (2015b). El sentido educativo del non sense surrealista en la creación literaria infantil. En P. Miralles y T. Izquierdo (Eds). Propuestas de innovación en Educación Infantil (pp. 273-282). Murcia: Editum

Chocobar, C. N. (2015c). La luna viene a la fragua. Poesía para jugar con los sueños. En O. Cleger y J. M. De Amo (Eds.). La Educación literaria y la e-literatura desde la minificción. Enfoques hipertextuales para el aula. (pp. 673-687). Barcelona: Universitat de Barcelona.

Colás, M.P., De Pablos, J. y Ballesta, J. (2018). Incidencia de las TIC en la enseñanza en el sistema educativo español: una revisión de la investigación. RED. Revista de Educación a Distancia,. 56. Recuperado de https://www.um.es/ead/red/56/colas_et_al.pdf

De la Torre, S., y Violante, V. (Coord. y Dir.) (2006). Comprender y evaluar la creatividad. (Vol. 1). Málaga: Ediciones Aljibe.

De Vicente-Yagüe, Ma I. (2013). La intertextualidad literario-musical. Una estrategia didáctica para la animación a la lectura y la audición musical. Barcelona: Octaedro.

De Vicente-Yagüe, M. I. (2014). Estudio y valoración de un modelo didáctico intertextual literario-musical. Una investigación en la Región de Murcia. Revista de investigación educativa, RIE, 32 (2), 513-532.

Díaz-Aguado, M. J. (2003). Educación intercultural y aprendizaje cooperativo. Madrid: Pirámide.

García Ferrando, M. (1986). La encuesta. En M. García; J. Ibañez y F. Alvira (Comps.). El análisis de la realidad social. Métodos y técnicas de investigación. Madrid: Alianza.

González, J. y Wagenaar, R. (2006). Una introducción a Tuning Educational Structures in Europe. La contribución de las universidades al proceso de Bolonia. Programa Socrates-Tempus. Recuperado de: http://www.unideusto.org/tuningeu/images/stories/ documents/General_Brochure_Spanish_version.pdf

González, M. (2013). El cine y la literatura en el desarrollo y logro de las competencias básicas. Análisis e interpretación de una investigación intertextual en Educación Primaria y Secundaria. (Tesis Doctoral). Murcia: Universidad de Murcia. Recuperado de http://digitum.um.es/xmlui/handle/10201/36742

González, M. (2015a). Literatura e intertextualidad. Literatura y cine: competencias de la imaginación. En P. Guerrero y M. T. Caro (Coords.). Didáctica de la Lengua y Educación Literaria (pp. 389-398). Madrid: Ediciones Pirámide. 
Creación surrealista de sueños colectivos en Educación Primaria. Investigación-acción intercultural

Cynthia Nathaly Chocobar

González, M. (2015b). Cine y literatura para el aprendizaje de las competencias básicas: vínculos semióticos y educativos. Educatio Siglo XXI, 33 (1), 175-194.

González di Pierro, C. (2014). Educación intercultural y competencia participativa en educación primaria. Base de la comunicación etnográfica. En Sánchez Martín, M. et al. (eds.), Investigación educativa en las aulas de primaria (PP. 485-496). Murcia: Editum.

Gordon, W. J. J. (1963). Sinéctica. El desarrollo de la capacidad creadora. México: Editorial Herrero Hermanos Sucesores.

Guerrero, P. (2008). Metodología ekfrástica de la creación literaria. Murcia: DM.

Guerrero, P. (2015). Literatura y bellas artes. En P. Guerrero y M. T. Caro (Coords.), Didáctica de la Lengua y Educación Literaria (pp. 365-376). Madrid: Ediciones Pirámide.

Guilford, J.P. (1991). Creatividad y educación. Barcelona: Paidós.

Iglesias-Cortizas, M. J. y Rodicio-García, M. L (2013). El desarrollo de la creatividad e innovación. Un reto ante la crisis actual. Revista de Investigación en Educación, 11 (1), 134-148.

Jonnaert, Ph., Barrette, J., Boufrahi, S., Masciotra, D. (2005). Contribution critique au développement des programmes d'études: competences, constructivisme et interdisciplinarité. Note de synthèse. Revue des Sciences de l'Éducation, 30 (3), 667 696.

Kemmis, S. (1989). Investigación en la acción. En T. Husen; T. N.Postlehwaite. Enciclopedia Internacional de la educación. Vol. 6, Barcelona: Vicens-Vives, pp.3330-3337.

Klimenko, O. (2008). La creatividad como un desafío para el siglo XXI. Educación y Educadores, 11, 191-210.

Landow, G. P. (1996). Hipertexto. La convergencia de la teoría crítica contemporánea y la tecnología. Barcelona: Paidós.

Latorre, A. (2003). La investigación-acción. Conocer y cambiar la práctica educativa. Barcelona: Graó.

Lavega, P., Sáez de Orcáriz, U., Lasierra, G. y Salas, C. (2013). Intradisciplinariedad e interdisciplinariedad en la adquisición de competencias: estudio de una experiencia de aprendizaje cooperativo. Revista electrónica interuniversitaria de formación del profesorado, 16 (1), 133-145.

Llopis, C. (2011). Aprendizaje cooperativo. Crítica., 972, 37-41.

Lorenzo, F. (2016). Competencia en comunicación lingüística: claves para el avance de la comprensión lectora en las pruebas PISA. Revista de Educación, 374, 142-160. DOI: 10.4438/1988-592X-RE-2016-374-329.

Marín, N. y Soler, M. (2004). Una comunidad de aprendizaje. Cuadernos de pedagogía, $331,60-62$.

Mendoza, A. (2001). El intertexto lector. Cuenca: Ediciones de la Universidad de CastillaLa Mancha.

Mendoza, A. (Coord.) (2012). Leer hipertextos. Del marco hipertextual a la formación del lector literario. Barcelona: Octaedro.

Molina, C. (2015). Literatura e intertextualidad. Literatura y Pintura: ékfrasis creativa. En P. Guerrero y M. T. Caro (Coords.). Didáctica de la Lengua y Educación Literaria (pp. 399-411). Madrid: Ediciones Pirámide. 
Creación surrealista de sueños colectivos en Educación Primaria. Investigación-acción intercultural

Cynthia Nathaly Chocobar

Morin, E. (1999). Los siete saberes necesarios para la educación del futuro. Barcelona: Paidós. Moya, J. y Luengo, F. (cords.) (2011). Teoría y práctica de las competencias básicas. Barcelona: Graó.

Murga-Menoyo, M. A. (2015). Competencias para el desarrollo sostenible: las capacidades, actitudes y valores meta de la educación en el marco de la Agenda global post-2015. Foro de Educación, 13(19), 55-83. doi: http://dx.doi.org/10.14516/ fde.2015.013.019.004

OCDE (2005). La definición y selección de competencias clave. Resumen ejecutivo. Paris: OCDE. Recuperado de http://www.deseco.admin.ch.

OCDE (2009). Pisa 2009. Marco de evaluación. Conocimientos y habilidades en Ciencias, Matemáticas y lectura. Madrid: MEC. Recuperado de http://www.educacion.es/dctm/ ministerio/horizontales/prensa/notas/2010/20101207-pisa2009-informe-espanol. pdf?documentld=0901e72b806ea35a

Paz, O. (1974). La búsqueda del comienzo (escritos sobre el surrealismo). Madrid: Editorial Fundamentos.

Pérez, A. I. (2007). La naturaleza de las competencias básicas y sus implicaciones pedagógicas. Cuadernos de Educación 1. Cantabria: Gobierno de Cantabria. Recuperado de http://www.ceyi-cantabia.com/

Perrenoud, P. (2012). Cuando la escuela pretende preparar para la vida. ¿Desarrollar competencias o enseñar otros saberes?. Barcelona: Graó.

Prensky, M. (2015). El mundo necesita un nuevo currículo. Habilidades para pensar, crear, relacionarse y actuar. Madrid: SM.

Rodari, G. (2011). Gramática de la fantasía. Barcelona: Editorial Planeta.

Roegiers, X. (2007). Pedagogía de la integración. Competencias e integración de los conocimientos en la enseñanza. San José: Coordinación Educativa y Cultural Centroamericana y $\mathrm{AECl}$.

Romea, C. (2001). ¿Qué une y qué separa al cine y a la literatura?. En Pujals, G. y Romea, C. (Coords.) (2001). Cine y literatura. Relación y posibilidades didácticas (pp. 17-36). Barcelona: Horsori.

Romea, C. (2010). A vueltas con 'Alicia en el país de las maravillas'. Aula de Innovación Educativa. 192, 75 - 76.

Romea, C. (2011): Cine de literatura poderoso binomio educativo y cultural. Lenguaje y Textos, 34, 29-39.

Schleicher, A. (2006). Fundamentos y cuestiones políticas subyacentes al desarrollo de PISA. Revista de Educación, número extraordinario, 21-43. Recuperado de http:// www.revistaeducacion.mec.es/re2006/reextra2006a04.pdf

Tejerina, I. (2008). Leer la interculturalidad. Una propuesta didáctica para la ESO desde la narrativa, el álbum y el teatro. Santander: Conserjería de Educación del Gobierno de Cantabria.

Torrance, P. (1998). Educación y capacidad creativa. Madrid: Morova.

Touriñan López, J. M. (2008) Educación en valores, educación intercultural y formación para una convivencia pacífica. La Coruña: NETBIBLO.

Trujillo, F. (2016). Aprendizaje basado en proyectos. Madrid: Ministerio de Educación, Cultura y Deporte. 
Creación surrealista de sueños colectivos en Educación Primaria. Investigación-acción intercultural

Cynthia Nathaly Chocobar

UNESCO (2005). Hacia las sociedades del conocimiento. Mayenne: Ediciones UNESCO. Recuperado de http://unesdoc.unesco.org/images/0014/001419/141908s.pdf

Valverde, M. T. (2015). Desarrollo de la competencia escrita con recursos TIC. En P. Guerrero y M. T. Caro (Coords.), Didáctica de la Lengua y Educación Literaria (pp. 429 -452). Madrid: Ediciones Pirámide. 